\title{
Validation of Educational Video to Promote Self-Efficacy in Preventing Childhood Diarrhea
}

\author{
Ludmila Alves do Nascimento, Andressa Peripolli Rodrigues, Emanuella Silva Joventino, \\ Neiva Francenely Cunha Vieira, Patrícia Neyva da Costa Pinheiro, \\ Lorena Barbosa Ximenes \\ Department of Nursing, Federal University of Ceará, Fortaleza, Brazil \\ Email: ludmilaalves@hotmail.com
}

Received 11 January 2015; accepted 3 February 2015; published 10 February 2015

Copyright (C) 2015 by authors and Scientific Research Publishing Inc.

This work is licensed under the Creative Commons Attribution International License (CC BY). http://creativecommons.org/licenses/by/4.0/

(c) (i) Open Access

\section{Abstract}

The aim of this study was to evaluate and to validate an educational video to promote maternal self-efficacy in preventing childhood diarrhea with women assisted in a health unit. Validation study, developed with 17 mothers whose children were under five years old, was analyzed on scenes of an educational video according to the validity of appearance (clarity/comprehension) and of content (relevance). The scenes were considered clear and comprehensive with a perceptual above $70 \%$ and with an average of $96.9 \%$ of agreement. Regarding the relevance, the agreement was maintained between $94 \%$ and $100 \%$, however only scenes 03 and 13 presented $76.6 \%$ and $70.6 \%$ of agreement respectively. Global Content Validation Index of the educational video scenes was 0.97 meaning an excellent level of agreement among mothers. The video showed to be a valid and a trustworthy material to promote maternal self-efficacy in preventing childhood diarrhea. Therefore, it is important that the material is disseminated in other health services so that other mothers may have contact with the same, providing greater reliability of the material.

\section{Keywords}

Diarrhea, Infantile, Self Efficacy, Educational Technology, Health Education, Nursing

\section{Introduction}

Infant diarrhea is a common manifestation of infectious and parasitic diseases that persists as a major public health problem in Brazil [1]. It is known that proper handling and treatment of diarrhea provide rapid solving to 
the case, however, knowing the factors that predispose to diarrhea does not mean that there will be better health behaviors, because mothers may perform preventive behaviors against the disease even if they do not have enough knowledge about the risk factors of the disease [2].

Thus, in addition to knowledge about the preventive measures of diarrhea, it is considerable to use maternal selfefficacy attributed to children in care, as it is a potentially modifiable construct, amenable to particular interventions that can generate positive results in the health status of people in levels of motivation and adherence to healthy behaviors [3].

Therefore, an educational video was built from the Self-efficacy Scale for the Prevention of Infant Diarrhea (SESPID) that consists of 24 items including the following factors/areas: family hygiene, with 15 items and food/general practices, with 9 items [2]. This educational video "Childhood Diarrhoea: you are able to prevent it" may be one of the major resources used by nurses in the health education activities in the dissemination of preventive measures against diarrheal diseases.

In order for educational materials meet the real needs of the target population for which it is intended, the validation of the same should be made with either as specialized judges by a panel of "lay" people, because they know these are the realities that surround and that will use the technology proposed [4]. From its validation, educational video will serve as a tool for use by health professionals to promote mothers' self-efficacy about infant diarrhea, favoring their empowerment for prevention and control of disease, making them able to take care of their children effectively and safely and promoting health and preventing disease.

Given the above, this study aimed to evaluate and validate an educational video for promoting maternal self-efficacy in preventing childhood diarrhea with care at a health facility located in Fortaleza, Ceará/Brazil women.

\section{Method}

\subsection{Design and Sample}

It is a methodological study that proposes to carry out the process of validation of content and appearance of an educational video focusing on the promotion of maternal self-efficacy in preventing childhood diarrhea.

Data collection was conducted in June 2013 with 17 mothers of children under five years who were treated in a health facility belonging to the Regional Executive Secretary III (RE III), Fortaleza-CE, as recommended by some authors whom advise that a number 06-20 subject to validation of technologies/tools were necessary [5]. We emphasize that we chose an odd number of subjects to prevent the tie in dubious questions and answers [6].

Thus, we adopted the following inclusion criteria: mothers with at least one child under five years old who were treated at the health unit said. The exclusion criteria was mothers having difficulty understanding to assess the educational video.

It was a convenience sample, in which mothers awaiting care at the clinic were invited to participate in the study with the clear objective of the same. Besides obtaining the agreement of the participants it was applied the terms of informed consent. The mothers got one of the informed consent.

\subsection{Measures}

The educational video entitled "Infantile Diarrhea: you are able to prevent it" was developed from the items of the Self-efficacy Scale for the Prevention of Infant Diarrhea (SESPID) [2] [4]. At first, there was a development joint with the technical producer of a script and a storyboard. This deals with the representation of scenes in script form of sequential drawings, similar to a comic book in order to facilitate the work of the production team during the video recording. This has duration of 16 minutes and was produced in the Laboratory of Health Communication (Lab-Com Health) and in the community in order to provide a closer approximation to the clientele with the matter.

Video scenes focus on the items of SESPID with the objective of enabling increased self-efficacy from the mother to prevent childhood diarrhea, the following aspects addressed of care related to this grievance were: child hygiene (hand washing with soap and water, cutting the nails and bath), washing food, cleaning the home, the use of shoes for the children, the waste dump, healthy eating, breastfeeding, vaccination, treatment of drinking water and the preparation of oral rehydration serum. 
Validity is the property of measuring what an instrument or methodology is proposed. Thus, the content validation highlights the specific domain of content that is wanted to measure or transmit, while the validation of appearance consists in judging educational resource regarding clarity, understanding and presentation of the same, indicating whether the measure apparently measures or transmits what you want [6].

It is worth mentioning the importance of validation of educational materials are evaluated by the target audience, as they will make use of these technological tools, so certain is required to make sure that they are understandable to those [7].

Thus, it is needed the use of instruments that can assess the quality of these resources that will be available to the community. To this end, a variety of instruments have been used in this process of evaluation of educational materials [7] [8]. However, this study used an adapted form of evaluation of educational material, which was validated by two experts in the field that included the following areas: understanding, attractiveness, self-efficacy, cultural acceptability and persuasion of educational material [8] [9]. In addition, this form contained a checklist for relevance, relevance and degree of clarity and/understanding of educational video scenes addressed in addition to sociodemographic characteristics of women [4] [10].

The application of educational video had an average duration of 16 minutes and it was presented to women in groups: three groups composed of four mothers and one group of five. Shortly thereafter, individual interviews were conducted using the above instrument in a private room, with an average duration of 15 minutes. Data collection was performed by an academic nursing and four nurses previously trained.

\subsection{Analytic Strategy}

Data were analyzed, organized and processed by the Statistical Package for Social Sciences (SPSS) version 20.0 and presented in tables and graphs. Furthermore, to examine the validity of content of the educational video it was used the Content Validity Index (CVI) and it was calculated based on three mathematical equations: the S$\mathrm{CVI} /$ Ave (average of the indexes content validation for all indexes scale), S-CVI/ UA (proportion of items in a scale that reaches scores 3 really relevant and 4 highly relevant for all judges) and the I-CVI (content validity of individual items) [11]. It is noted that the CVI varies from -1 to 1 , and the item is considered valid when agreement among judges is equal to or greater than 0.80 [12].

Regarding the validity of appearance, it was considered as clear and understandable the scenes that achieved an agreement of at least $70 \%$ of the judges, and this condition can vary from $70 \%$ to $80 \%$ [2].

The study was submitted to the Ethics Committee in Research and was approved by Purport 106/12. In view of this, the ethical aspects of research involving human beings were respected in accordance with the recommendations by Declaration of Helsinki.

\section{Results}

According to the application of educational video the 17 mothers had a mean age of 27 years, $47.1 \%$ (08) had primary school education and $64.7 \%$ (11) were in a consensual union and were housewives. Still, $47.1 \%$ (08) lived with three people in the home and $29.4 \%$ (05) lived with a family income of a minimum wage per month. Regarding the number of pregnancies, $52.9 \%$ (9) had one child, $88.2 \%$ (15) had the most abortions and 58.8\% (10) of the children were male.

With regard to socioeconomic and health conditions, $82.4 \%$ (14) of the houses were plastered and 58.8\% (10) had tile floors. All houses had regular collection of household waste system, while 35.3\% (06) show that, sometimes, there were flies in the household. Almost all the houses, $94.1 \%$ (16), was supplied by water from the public network, however, to offer your child, 70.6\% (12) of the mothers used water sold, and $176 \%$ (03) of these chose to boil or filter water.

When it come to the location of the taps in the home, $52.9 \%$ (9) of the respondents had at least three rooms, with soap for handwashing near the sinks; and $58.8 \%(10)$ had a flush toilet water. Of the study participants, 94.1\% (16) were using the public sewage system, besides having cooler running on residence and not breed animals in the household.

Regarding the opinion of women about the educational video, all said that the scenes presented helped to have a better understanding about the subject. The scenes of the video were considered clear, with a percentage above 
$70 \%$ and with an average of $96.9 \%$ concordance among women. Only two scenes (3:13), referring to the expiry date of the food and the treatment of drinking water, showed percentile around $70 \%$, the other had $100 \%$ agreement among the participants (Figure 1).

About the relevance of the educational video scenes the correlation remained between $94 \%$ and $100 \%$, however, only the scenes $3: 13$, concerning the validity of the treatment of food and drinking water, respectively, showed $76.6 \%$ and $70.6 \%$ concordance among women (Figure 2).

The CVI calculations of individual scenes are presented in Table 1 which ranged from 0.88 to 1.00 . As for the global CVI educational video was found a value of 0.97 , meaning excellent level of agreement between mothers with regard to the content of the video.

With regard to the assessment tool of educational material, we can notice that the video "Children Diarrhea: you are able to prevent it" had good understanding, presenting scenes that promoted attractiveness and self-efficacy and having a language that favored cultural acceptance and persuasion by the audience, according to Table 2.

Given the domains assessed on this educational material, it can be seen that 76.5\% (13) of the mothers understood the concept of diarrhea and were able to say that all the care for the prevention of disease, stating that they understood all parts of the video $100 \%$ (17) and also stated unanimously that they felt motivated to watch the video until the end, demonstrating the attractiveness of the video.

With respect to cultural acceptance, 82.4\% (14) agreed with the theme that brought the video and do not felt uncomfortable with what was covered in it. However, $17.7 \%$ (03) women emphasized that the scene 04, which refers to the washing of fruits and vegetables with bleach caused little discomfort.

Regarding the field of self-efficacy, 88.2\% (15) of women believed they could follow the guidelines indicated in the video in its daily, $100 \%$ (17) stated that the scenes have allowed mothers to think about their health and his child and 94.1\% (16) felt confident to prevent diarrhea in her child. Persuasion in the field, 94.1\% (16) said they would be able to advise other mothers in relation to preventive care and management of childhood diarrhea (Table 2).

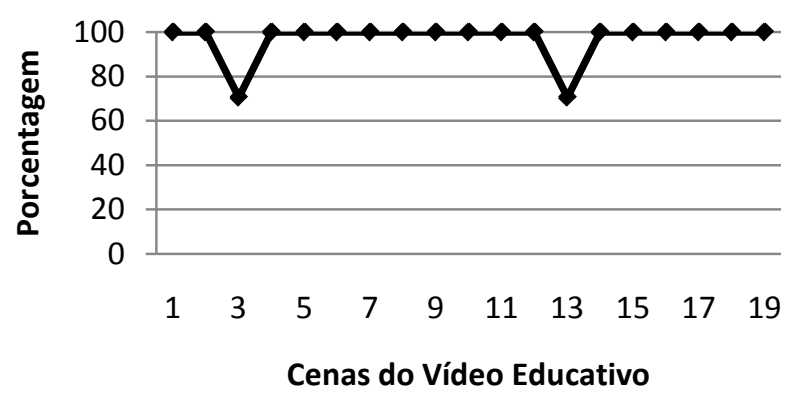

Figure 1. Clarity of the scenes of the video "Children Diarrhea: you are able to prevent it”. Fortaleza, Ceará/Brazil, 2013.

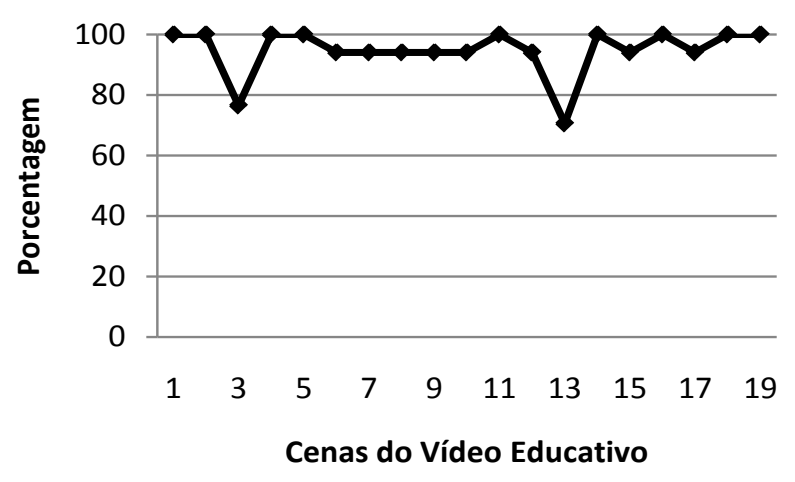

Figure 2. Relevance of the scenes from the video "Infant Diarrhea: you are able to prevent it”. Fortaleza, Ceará/Brazil, 2013. 
Table 1. Distribution of Content Validity Index (CVI) of each scene, according to the analysis of mothers. Fortaleza, Ceará/Brazil, 2013.

\begin{tabular}{|c|c|c|}
\hline Scenes & Scenes & CVI \\
\hline 1 & Child hygiene & 1.00 \\
\hline 2 & Hand washing & 1.00 \\
\hline 3 & Food expiration date & 1.00 \\
\hline 4 & Fruit and vegetables washing & 1.00 \\
\hline 5 & Cleaning the place of food preparation & 1.00 \\
\hline 6 & Storing food in the refrigerator & 0.94 \\
\hline 7 & Food/drinks protection against insects & 0.94 \\
\hline 8 & House cleaning & 0.94 \\
\hline 9 & Disposing of household waste & 0.94 \\
\hline 10 & Child's contact with soil/sand & 0.88 \\
\hline 11 & Health feeding & 1.00 \\
\hline 12 & Storing leftovers & 0.94 \\
\hline 13 & Treatment of drinking water & 0.94 \\
\hline 14 & Exclusive Breastfeeding & 1.00 \\
\hline 15 & Cuttinh the child's nail & 0.94 \\
\hline 16 & Vaccination & 1.00 \\
\hline 17 & Taking the child to the health care center & 0.94 \\
\hline 18 & Preparation of oral rehydration solution & 1.00 \\
\hline 19 & Feeding during diarrhea & 1.00 \\
\hline
\end{tabular}

Table 2. Distribution of answers obtained by mothers according to evaluation domains from the educational material. Fortaleza, Ceará/Brazil, 2013.

\begin{tabular}{|c|c|c|}
\hline Domains & $\mathbf{N}$ & $\%$ \\
\hline \multicolumn{3}{|l|}{ Comprehension } \\
\hline \multicolumn{3}{|l|}{ Are you able to tell when your child has diarrhea? } \\
\hline Yes & 13 & $76.5 \%$ \\
\hline No & 4 & $23.5 \%$ \\
\hline \multicolumn{3}{|c|}{ Are you able to quote required care to be developed to prevent diarrhea in your child? } \\
\hline Yes & 17 & $100 \%$ \\
\hline No & - & - \\
\hline \multicolumn{3}{|c|}{ Are you able to identify parts of the video that you did not understand or found difficult? } \\
\hline Yes & 17 & $100 \%$ \\
\hline No & - & - \\
\hline \multicolumn{3}{|l|}{ Attractiveness } \\
\hline Did you feel like watching the movie to the end? & & \\
\hline
\end{tabular}




\section{Continued}

$\begin{array}{ccc}\text { Yes } & 17 & 100 \% \\ \text { No } & - & \\ \text { Cultural Acceptance } & & \\ \text { Is there something in this video that you think it is aggressive, } \\ \text { bad that bothers you or that you don't agree? } \\ \text { Yes } & 03 & 17.7 \% \\ \text { No } & 14 & 82.4 \% \\ \text { Self-efficacy } & & \\ \text { Yes } & & 88.2 \% \\ \text { Sometimes } & 15 & 5.9 \% \\ \text { No } & 01 & 5.9 \%\end{array}$

Did the video suggested "thinking or acting” about your and your children's health?

Yes

No

Did the video made you feel confident to prevent diarrhea in your child?

Yes

No

Persuasion

Do you think the video gives you sufficient knowledge to inform other moms on how to prevent childhood diarrhea?

Yes

No
01

\section{Discussion}

Infant diarrhea is a disease historically known as the easily preventable, but still as a serious public health problem, probably due to its multifactorial nature, consisting of bacteria, viruses, parasites, environmental and socioeconomic factors. Studies show that the high prevalence of childhood diarrhea is associated with reduced maternal knowledge, poor education and age, as well as households with poor sanitation conditions, and numerous families with low income [13].

Mothers who participated in the assessment and validation process of educational video showed similar characteristics to the aforementioned studies regarding low education, low purchasing power and large families, similar to the target audience for which the video was produced sociodemographic profile. This demonstrates their qualification in infer considerations regarding the proposed educational material. They not only achieve to understand the guidelines addressed in the video, but also evaluated as understandable and reliable to be disseminated to other women.

The validation of educational video by the mothers, called laypersons, is of paramount importance; since studies show that it is them whom will make the use of educational technology, and it is necessary to know the population to which the material is intended [4]. These women should be recognized as agents of their own history, but they must take a critical look at the reality in which they operate and should therefore be recognized and expanded its participation during the validation of the produced materials [14].

The validation performed by the participants of the study showed that the material built is reliable, since it 
obtained favorable results (individual and overall above $0.80 \mathrm{CVI}$ ) to construct one wished to evaluate (maternal self-efficacy for the prevention of childhood diarrhea).

Most participants considered both the scenes of the video light, as understandable and relevant, thus achieving a margin of over $70 \%$ acceptance, which confirms the percentage recommended by the literature. Also confirming the adequacy of the scenes and the significance of the information contained in the text and helping the mother in understanding the content. Only the scenes 3:13, referring to the expiry date of the food and the treatment of drinking water, respectively, had lower $70 \%$ percentile. Being only suggested that for the scene 03 would add foods that are consumed by the child. However, it is worth mention that although the scene 03 have been shown just a bag of rice at other times in the video it was addressed healthy eating and its importance for the children in addition to their feeding during the episode diarrheal [15].

Despite the lack of suggestions for amendments to the scene 13, we know the importance of treating water for consumption, since it is one of the main measures for the prevention of the disease and if done correctly can reduce the number of deaths from diarrhea [16].

Regarding the domains assessed by the women on the proposed educational material, it was shown that educational technology has obtained positive results, since the video allowed not only mothers to understand about the concept of prevention and management of childhood diarrhea, as the scenes enabled an assimilation of content, in a persuasive and attractive form being appropriate to their culture thus fostering motivation and maternal confidence to feel able to perform a specific and desired behavior [8].

Understand the information in the proposed educational video is an area that needs to be covered satisfactorily, because it will help the mothers know how to identify when a child has diarrhea and what measures should adopt, in addition to management and treatment. Considering that the disease has a rapid resolution, provided that all the measures mentioned above are adequately performed [17].

The attractiveness in educational materials should be addressed not only in audiovisual materials, but in all educational technologies, since it stimulates customer interest until the end of the application of the educational strategy; in addition to promoting learning and increasing the nurse-patient interaction. Study shows that the materials must meet standards when it comes to the layout, the images used, the colors and the font size of the textual information presented so that the video will become the most attractive possible [18] [19].

The domain of cultural acceptance is also essential for the validation of educational material, since the culture of someone is linked to his/hers values and knowledge to the world that lives [18]. Soon, the mothers' perceptions regarding what is being discussed identify whether the concepts and guidelines are transmitted according to the reality they experience, because they will only follow the guidelines if they believe is right and feasible in their daily lives.

Regarding self-efficacy, it should be considered in the care provided to children, because encouraging mothers, transform their actions, influencing the events that affect their lives [2]. Thus, self-efficacy will interfere with the amount of effort that each individual will dispense and time that will persist to overcome obstacles and adverse experiences. However, necessarily guarantee success, but certainly produces low self-efficacy failure [20].

In the educational video, the domain persuasion was employed effectively because the information contained in the scene gave the opportunity of adoption healthy behaviors, so persuasive communication is a useful strategy to generate preventive behaviors, as can be evidenced from the statements mothers who believe be able to advise other women to act according to the message conveyed by the video [21].

\section{Conclusions}

The video "Childhood Diarrhea: you are able to prevent it" was shown to be a valid and reliable educational material for the promotion of maternal self-efficacy in preventing childhood diarrhea, and timely use in educational activities performed by nurses. It can be used with patients, but must be of further way to nurses' work and must be disseminated in other services for other mothers.

A limitation of the study lies in the fact that the study participants are only of one health facility, thus preventing a more comprehensive assessment of the population in general.

\section{Acknowledgements}

We would like to thank all participants in the study. 


\section{References}

[1] Oliveira, T.C.R. and Latorre, M.R.D.O. (2010) Trends in Hospital Admission and Infant Mortality from Diarrhea: Brazil, 1995-2005. Revista de Saúde Pública, 44, 102-111. http://www.scielosp.org/pdf/rsp/v44n1/en 11.pdf http://dx.doi.org/10.1590/S0034-89102010000100011

[2] Joventino, E.S., Oriá, M.O.B., Sawada, N.O. and Ximenes, L.B. (2013) Apparent and Content Validation of Maternal Self-Efficiency Scale for Prevention of Childhood Diarrhea. Revista Latino-Americana de Enfermagem, 21, 1-9. http://www.scielo.br/pdf/rlae/v21n1/v21n1a12.pdf http://dx.doi.org/10.1590/S0034-89102010000100011

[3] Salvetti, M.G. and Pimenta, C.A.M. (2007) Chronic Pain and the Belief in Self-Efficacy. Revista da Escola de Enfermagem da USP, 41, 135-140. http://www.scielo.br/scielo.php?script=sci_arttext\&pid=S0080-62342007000100018 http://dx.doi.org/10.1590/S0080-62342007000100018

[4] Joventino, E.S., Ximenes, L.B., Almeida, P.C. and Oriá, M.O.B. (2013) The Maternal Self-Efficacy Scale for Preventing Early Childhood Diarrhea: Validity and Reliability. Public Health Nursing, 30, 150-158. http://dx.doi.org/10.1590/S0080-62342007000100018

[5] Alexandre, N.M.C. and Coluci, M.Z.O. (2011) Content Validity in the Development and Adaptation Processes of Measurement Instruments. Ciência \& Saúde Coletiva, 16, 3061-3068. http://www.scielo.br/scielo.php?pid=S1413-81232011000800006\&script=sci arttext http://dx.doi.org/10.1590/S0080-62342007000100018

[6] Oliveira, M.S., Fernandes, A.F. and Sawana, N.O. (2008) Educational Handbook for Self-Care in Women with Mastectomies: A Validation Study. Texto \& Contexto Enfermagem, 17, 115-123. http://www.scielo.br/pdf/tce/v17n1/13.pdf http://dx.doi.org/10.1590/S0104-07072008000100013

[7] Castro, M.S., Pilger, D., Fuchs, F.D. and Ferreira, M.B.C. (2007) Development and Validity of a Method for the Evaluation of Printed Education Material. Pharmacy Practice (Granada), 5, 89-94.

http://scielo.isciii.es/scielo.php?pid=S1886-36552007000200007\&script=sci_arttext

[8] Doak, C.C., Doak, L.G. and Root, J.H. (1996) Learner Verification and Revision of Materials. In: Doak, C.C., Doak, L.G. and Root, J.H., Eds., Teaching Patients with Low Literacy Skills, 2nd Edition, Lippincott Company, Philadelphia, 167-188.

[9] Negretto, G.W. (2011) Development and Evaluation of Printed Educational Material to Improve the Medication Compliance of Pediatric Patients after Hospital Discharge. Revista HCPA, 31, 443-450. http://seer.ufrgs.br/hcpa/article/view/23608/14953

[10] Dodt, R.C.M., Ximenes, L.B. and Oriá, M.O.B. (2012) Validation of A Flip Chart for Promoting Breastfeeding. Acta Paulista de Enfermagem, 25, 225-230. http://www.scielo.br/pdf/ape/v25n2/en_a11v25n2.pdf

[11] Polit, D.F. and Beck, C.T. (2006) The Content Validity Index: Are You Sure You Know What’s Being Reported? Critique and Recommendations. Research in Nursing \& Health, 29, 489-497. http://cfd.ntunhs.edu.tw/ezfiles/6/1006/attach/33/pta_6871_6791004_64131.pdf http://dx.doi.org/10.1002/nur.20147

[12] Norwood, S. (2000) Research Strategies for Advanced Practice Nurses. Prentice Hall Health, Upper Saddle River.

[13] Pereira, I.V. and Cabral, I.E. (2008) Acute Diarrhea in Lesser Children of One Year: Subsidies for the Delineation of Taking Care. Escola Anna Nery Revista de Enfermagem, 12, 224-229. http://www.scielo.br/pdf/ean/v12n2/v12n2a04.pdf http://dx.doi.org/10.1590/S1414-81452008000200004

[14] Freire, P. (1997) Pedagogia da autonomia: Saberes necessários à prática educativa. Paz e Terra, São Paulo.

[15] Brasil (2013) Ministério da Saúde. Dez passos para uma alimentação saudável: Guia alimentar para crianças menores de dois anos. Ministério da Saúde, Brasília.

http://bvsms.saude.gov.br/bvs/publicacoes/dez passos alimentacao saudavel guia.pdf

[16] Portela, R.A., Souto, W.M.S., Leite, V.D. and Torquato, S.C. (2011) The Incidence of Diarrheal Diseases and Their Relation with the Lack of Sanitation: A Literature Review. Revista Brasileira de Geografia Médica e da Saúde, 7, 150156.

[17] Brasil (2009) Ministério da Saúde. Secretaria de Vigilância em Saúde. Departamento de Vigilância Epidemiológica. Guia de Vigilância Epidemiológica. $7^{\text {a }}$ Edição, Ministério da Saúde, Brasília. http://bvsms.saude.gov.br/bvs/publicacoes/guia_vigilancia_epidemiologica_7ed.pdf

[18] Doak, C. and Doak, L. (2004) Pfizer Principles for Clear Health Communication: A Handbook for Creating Patient Education Materials That Enhance Understanding and Promote Health Outcomes. $2^{\mathrm{a}}$ Edition, Pfizer, New York.

[19] Reberte, L.M., Gomes, A.L.Z. and Hoga, L.A.K. (2012) Process of Construction of an Educational Booklet for Health Promotion of Pregnant Women. Revista Latino-Americana de Enfermagem, 20, 1-8. http://www.scielo.br/pdf/rlae/v20n1/14.pdf http://dx.doi.org/10.1590/S0104-11692012000100014 
[20] Bandura, A., Azzi, R.G. and Polydoro, S. (2008) Teoria Social Cognitiva: Conceitos básicos. Artmed, Porto Alegre.

[21] Tonani, M. and Carvalho, E.C. (2008) Cancer Risk and Preventive Behavior: Persuasion as an Intervention Strategy. Revista Latino-Americana de Enfermagem, 16, 1-8. http://www.scielo.br/pdf/rlae/v16n5/11.pdf http://dx.doi.org/10.1590/S0104-11692008000500011 
Scientific Research Publishing (SCIRP) is one of the largest Open Access journal publishers. It is currently publishing more than 200 open access, online, peer-reviewed journals covering a wide range of academic disciplines. SCIRP serves the worldwide academic communities and contributes to the progress and application of science with its publication.

Other selected journals from SCIRP are listed as below. Submit your manuscript to us via either submit@scirp.org or Online Submission Portal.
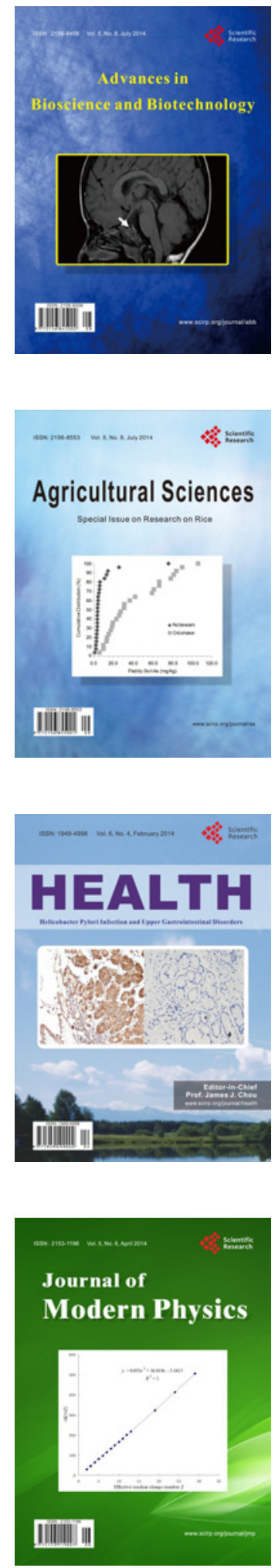
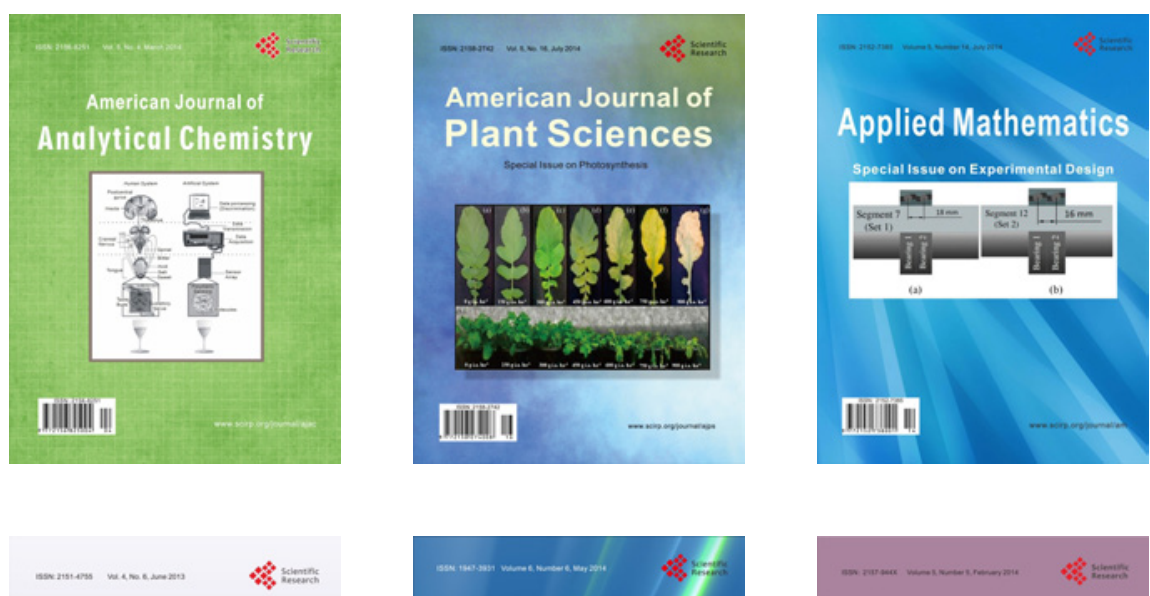

Creative Education
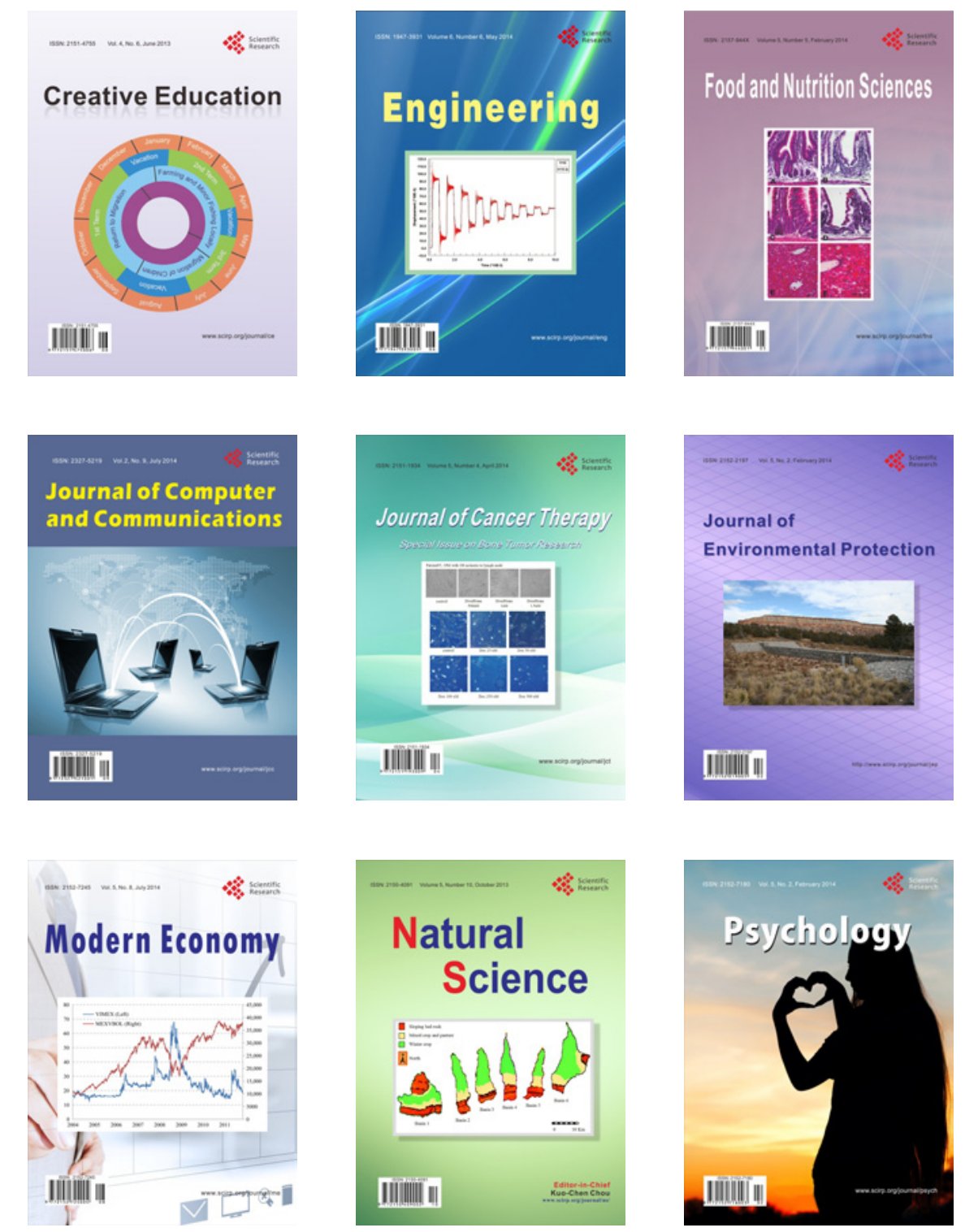